\title{
Retrieval of Precipitable Water Vapor by the Millimeter-Wave Imaging Radiometer in the Arctic Region During FIRE-ACE
}

\author{
James R. Wang, Paul E. Racette, and Michael E. Triesky
}

\begin{abstract}
Millimeter-wave radiometric measurements obtained from the NASA ER-2 aircraft over the arctic region on May 20, 1998, were used to estimate precipitable water $(P W)$ in the range $\leq 0.60 \mathrm{~g} / \mathrm{cm}^{2}$. The approach is a modified version of the recent work by Miao [1], which utilized the radiometric measurements at $150,183.3 \pm 3$, and $183.3 \pm 7 \mathrm{GHz}$ of the SSM/T-2 sensor to retrieve PW over the antarctic region. However, Miao has implicitly assumed a surface emissivity that is frequency independent over the 150-183 GHz range. This assumption turns out not to be a good one based on the airborne measurements described below, and the errors introduced in the PW estimation were substantial in many cases. It is shown below that four-frequency radiometric measurements in the frequency range of $150-220 \mathrm{GHz}$ provided a robust retrieval of $P W$, while allowing for a surface emissivity that varied linearly with frequency. The retrieved PW compared favorably with that calculated from rawinsonde data at two widely separated locations. The differences between the retrieved and calculated values are not more than $\pm 0.02 \mathrm{~g} / \mathrm{cm}^{2}$, which is smaller than errors associated with measurement uncertainty. It is found necessary to account for the double side-band nature of the 183.3 $\mathrm{GHz}$ measurements in the raditive transfer calculations for development of the retrieval algorithm. The PW values estimated from the algorithm developed from single side band, $183.3 \mathrm{GHz}$ radiative transfer calculations could be in error by as much as $\pm 0.10 \mathrm{~g} / \mathrm{cm}^{2}$. Finally, the effect of surface temperature variations is shown to introduce only a small error in the estimation of PW.
\end{abstract}

\section{INTRODUCTION}

$\mathbf{R}$ ECENTLY, there were a couple of studies on the retrieval of precipitable water (PW) over the polar regions, using the radiometric measurements near the $183.3 \mathrm{GHz}$ water vapor line from the Special Sensor Microwave/Temperature-2 (SSM/T-2) onboard the Defense Meteorological Satellite Project (DMSP) F-11 satellite [1], [2]. These studies provide a new method of estimating PW on a continental scale that could help determine water vapor budget in the high latitude regions (e.g., Antarctica). Monitoring the state of atmospheric water vapor and its transport into and out of these regions is important toward our understanding the state of balance of ice sheets and its effect on global sea level [3]. The method becomes feasible only when the atmosphere is relatively dry so that water vapor and surface emissivity can be estimated simultaneously from the multichannel measurements near the water vapor line of $183.3 \mathrm{GHz}$, as qualitatively illustrated earlier by Wang et al. [4].

Manuscript received March 21, 2000; revised August 9, 2000.

The authors are with the Laboratory for Hydrospheric Processes, NASA Goddard Space Flight Center, Greenbelt, MD 20771 USA (wang@sensor2.gsfc.nasa.gov).

Publisher Item Identifier S 0196-2892(01)02094-0.
Moore [2] used the measurements from the $183.3 \pm 3$ and $183.3 \pm 7 \mathrm{GHz}$ channels of the SSM/T-2 and the surface temperature values derived from European Center for Medium-Range Weather Forecast (ECMWF, to estimate PW and surface emissivity simultaneously over Antarctica. On the other hand, Miao [1] initially applied the measurements from the $183.3 \pm 1,183.3$ \pm 3 , and $183.3 \pm 7 \mathrm{GHz}$ channels of the SSM/T-2 to the retrieval of PW over the Antarctica. The surface emissivities from these channels should be nearly identical and thus would not introduce error in the retrieval. But the useful range of this approach was limited to $\mathrm{PW}<0.2 \mathrm{~g} / \mathrm{cm}^{2}$. To extend the range of the retrieval to higher PW values, Miao was forced to use the combined measurements of $150,183.3 \pm 3$, and $183.3 \pm 7 \mathrm{GHz}$, assuming that the surface emissivities from these channels were nearly the same. While this assumption of frequency-independent surface emissivity might be valid in that particular study based on a comparison of retrieval results with rawinsonde data, the errors caused by deviation from such an assumption have not been discussed or assessed [1].

In this paper, we report the retrieval of PW over the arctic region from the radiometric measurements of millimeter-wave imaging radiometer (MIR) [5] onboard the ER-2 aircraft. The aircraft was stationed in Fairbanks, AK, and participated in the FIRE III First International Satellite Cloud Climatology Project (ISCCP) Regional Experiment III Arctic Cloud Experiment (ACE) during May 13-June 7, 1998 [6]. Onboard the same aircraft was the moderate resolution imaging spectrometer (MODIS) airborne simulator (MAS) [7], which could have provided surface temperature measurements along the flight track. Unfortunately, the thermal infrared channels of the MAS were not functional during the initial phase of the experiment, and the information of surface temperature was not readily available for MIR data analysis reported in this paper. As a consequence, the algorithm developed by Miao [1] was adopted here initially to retrieve PW from the MIR measurements and found to have difficulty in the assumption of frequency-independent surface emissivity. This is because MIR has an additional channel of measurements at $220 \mathrm{GHz}$, and the effect of frequency dependence of surface emissivity on PW retrieval can be readily examined. The algorithm is thus modified and improved to accommodate the frequency dependence of surface emissivity. The estimated PW from the new algorithm is found to compare favorably with that derived from rawinsonde data. The errors resulted from the assumption of frequency-independent surface emissivity is assessed from a comparison of PW values estimated from the original and new 


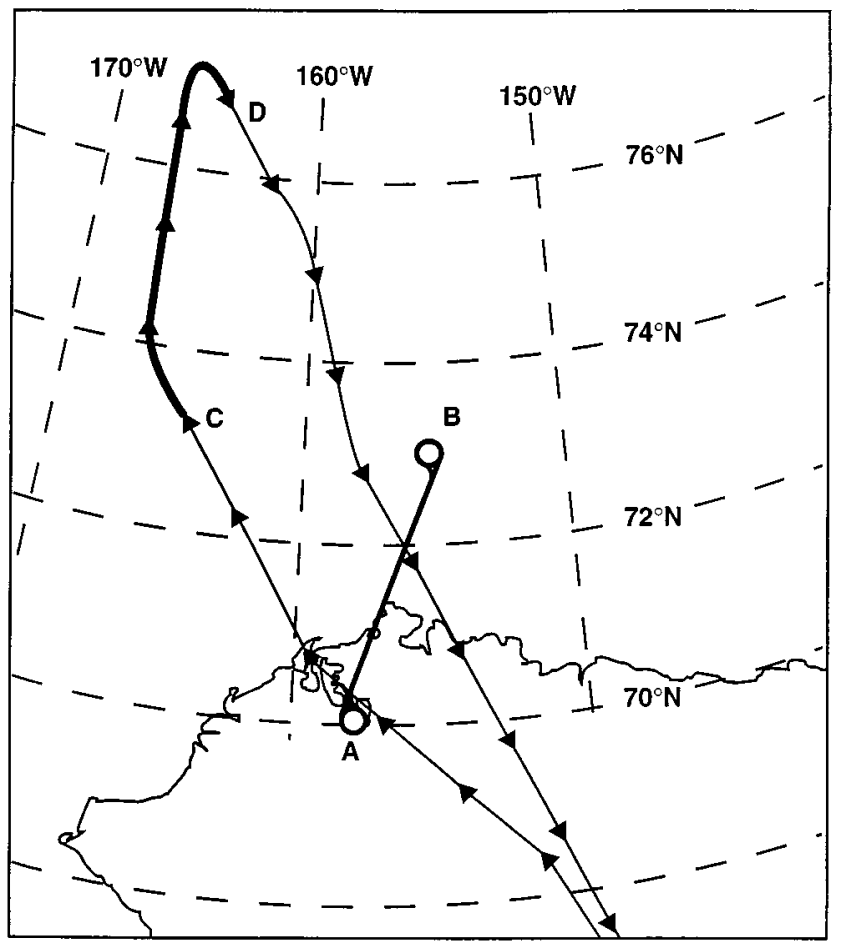

Fig. 1. Sketch showing the flight track of the ER-2 aircraft covering a latitude range of $70^{\circ} \mathrm{N}-77^{\circ} \mathrm{N}$. The segments $\mathrm{AB}$ and $\mathrm{CD}$ denoted by heavy solid curves correspond to time periods displayed in Figs. 7 and 8.

algorithms. Another two factors affecting the PW retrievals, not discussed by Miao [1], are also examined in the paper. These are the double side-band measurements around the $183.3 \mathrm{GHz}$ absorption line and the uncertainty in the surface temperatures used in the development of the retrieval algorithms.

\section{THE MEASUREMENTS}

From May 15 to June 6, 1998, the NASA ER-2 aircraft was deployed in Fairbanks and participated in a major field campaign sponsored by the NSF, NASA, NOAA, and DOE. The measurement program involved a number of aircraft and surface-based stations. Some of these measurements extended over several months to a year. The NASA component, the FIRE III First International Satellite Cloud Climatology Project (ISCCP) Regional Experiment III Arctic Cloud Experiment (ACE) consists mainly of the ER-2 aircraft, which contains a host of active and passive sensors covering a wide range of electromagnetic spectra. Among them is the MIR from Goddard Space Flight Center (GSFC), Greenbelt, MD, which measures radiation at seven different frequencies of $89,150,183.3 \pm 1,183.3 \pm 3$, $183.3 \pm 7,220$, and $340 \mathrm{GHz}$. The lowest five-frequency channels of the MIR are essentially identical to those of the SSM/T-2. As a consequence, the MIR measurements provide an excellent means of validating and extending the work of Miao [1] described previously. The instrument is a total-power cross-track scanning radiometer with a beamwidth of about $3.5^{\circ}$ independent of frequency. The temperature sensitivity is $\leq 1 \mathrm{~K}$ for all channels, and the calibration accuracy is within $\pm 2 \mathrm{~K}$ for channels $\leq 220 \mathrm{GHz}$. The $340 \mathrm{GHz}$ channel was installed and flown for the first time; a detailed analysis of data is needed to assess

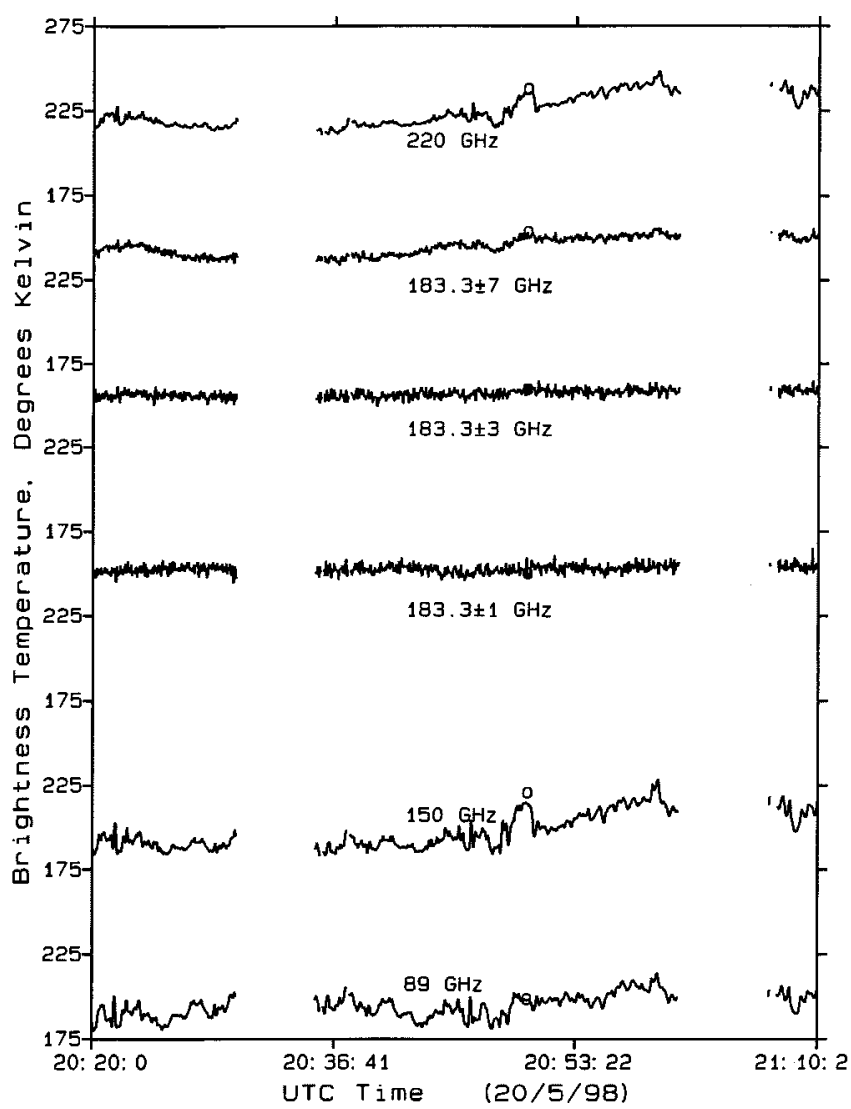

Fig. 2. Temporal variations of MIR brightness temperatures observed over the region denoted by segment $\mathrm{AB}$ of Fig. 1. The open circles are the calculated values over the water surface.

its calibration accuracy. The general operation and description of MIR can be found in Racette et al. [5].

The data set acquired by the MIR on May 20, 1998 was selected for this work because the measurements were made over an extended region of clear sky. Fig. 1 gives a sketch of the ER-2 aircraft flight track covering a latitude range of $68^{\circ} \mathrm{N}-75^{\circ} \mathrm{N}$. The aircraft took off around 1840 UTC and headed directly to Barrow $\left(71.3^{\circ} \mathrm{N}\right.$ and $\left.156.8^{\circ} \mathrm{W}\right)$. In the neighborhood of Barrow, the aircraft made four passes over the same area between waypoints $\mathrm{A}$ and $\mathrm{B}$, and then headed in the northwest direction toward waypoint $C$. It then changed direction and flew directly north to about $77^{\circ} \mathrm{N}$ latitude, and turned and headed back to Fairbanks. It flew over SHEBA camp located at $76^{\circ} 20.31^{\prime} \mathrm{N}$ and $166^{\circ} 37.45^{\prime} \mathrm{W}$. Data acquired from the whole flight were used in the retrieval of PW. The retrieved values of PW from the flight segments $\mathrm{AB}$ and $\mathrm{CD}$ only were shown and discussed in the sections below.

Fig. 2 shows the time variation of brightness temperatures $\left(T_{b}\right)$ measured by the six lower frequency channels of the MIR in the nadir direction along the flight segment $\mathrm{AB}$. The two data gaps in the figure correspond to the two endpoints of the flight segment where the aircraft was banking and making turns. The aircraft was flying over a region of open water off the coast of north Alaska for about 2 min centered around 2050 UTC. The $T_{b}$ values from the 150 and $220 \mathrm{GHz}$ channels are generally higher in this region than its immediate neighborhood. The open circles in the figure at $\sim 2050$ UTC give the $T_{b}$ values calculated for 

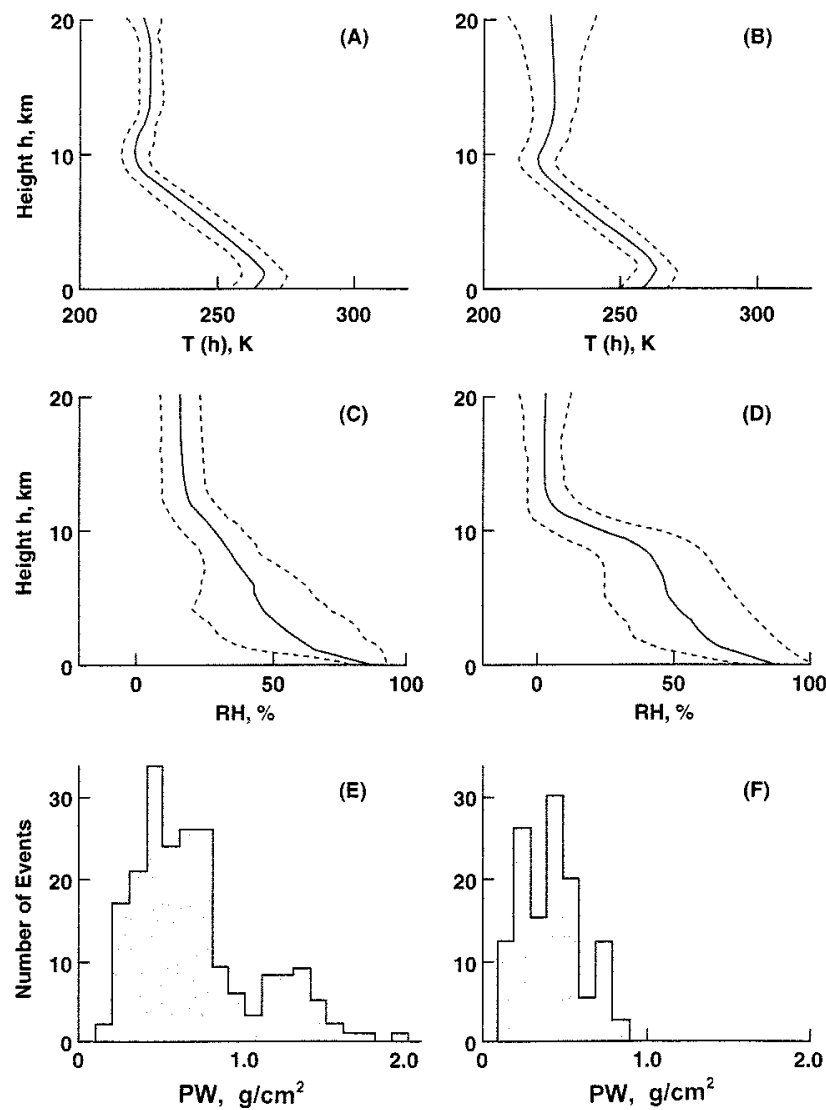

Fig. 3. Average temperature and relative humidity profiles and their standard devaitions, and histograms of integrated water vapor. (a), (c) and (e) Barrow (b), (d), and (f) SHEBA camp site.

the six frequency channels of the MIR from the Barrow rawinsonde data acquired close to the time of the flight. A calm water surface with a temperature of $273 \mathrm{~K}$ was assumed, and the dielectric permittivity model of Klein and Swift [8] as well as the atmospheric millimter-wave propagation model (MPM) model of Liebe [9] were used in the calculations. With the exception at $150 \mathrm{GHz}$, the observed and calculated $T_{b}$ values agree to within a couple of $\mathrm{K}$. The measured $T_{b}$ values at $150 \mathrm{GHz}$ are lower than the calculated ones by about 5-6 K. Part of this discrepancy could be traced to inadequate calibration for this channel, as another MIR ground-based measurement of down-welling millimeter-wave radiation in Barrow, AK, during March 1999 also showed lower than expected $T_{b}$ values. Another source of the discrepancy could be due to inaccurate results of the calculations. Using a more recent dielectric permittivity model of Stogryn et al. [13], the calculated $T_{b}$ values were lower by about $2 \mathrm{~K}$.

Ideally, one would like to retrieve PW from the three water vapor channels near $183.3 \mathrm{GHz}$ alone, because the surface emissivity for these channels would be nearly the same and could be simultaneously estimated in the retrieval process [2], [4]. However, the surface temperature will have to be measured at the same time in this approach, and the thermal infrared channels of the MAS were not functional during the first few days of flights, including the clear-sky flight on May 20, 1998. Instead, the method adopted by Miao [1] will be explored and modified
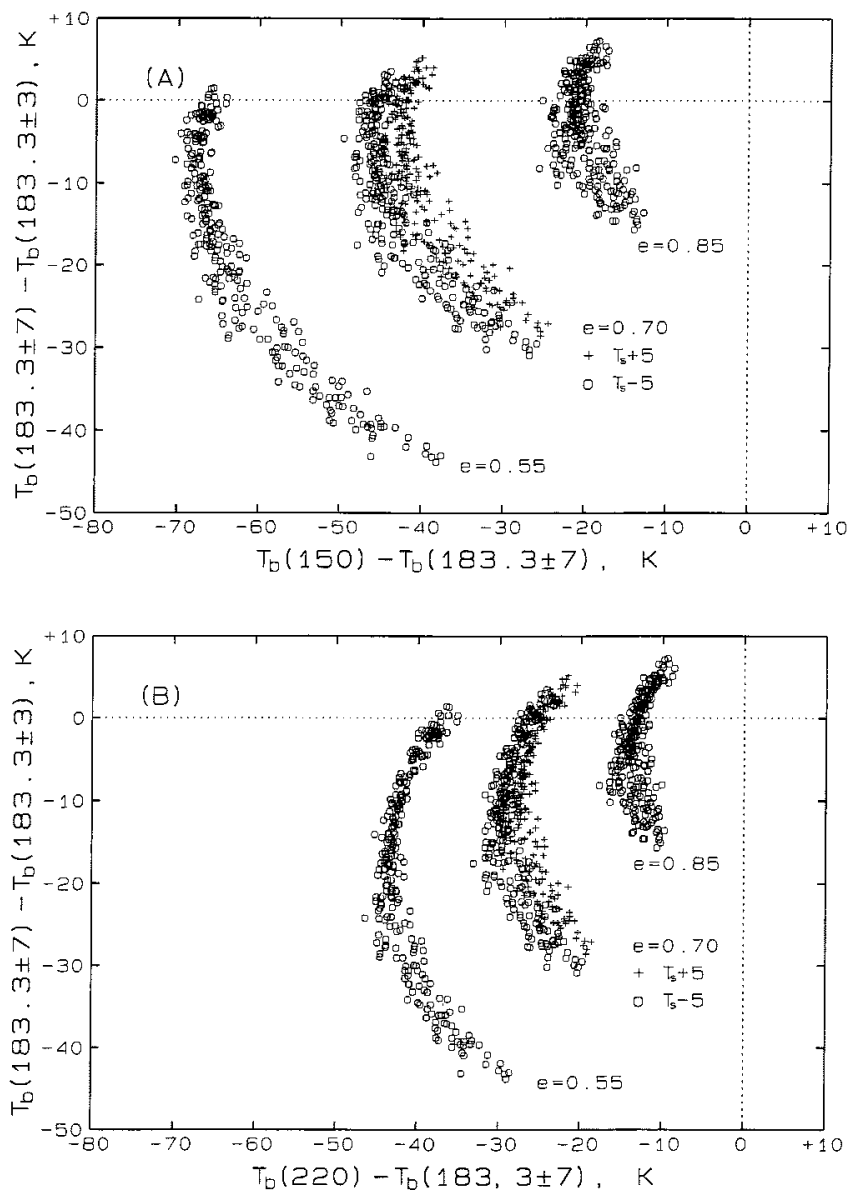

Fig. 4. Scatter plots of brightness temperature differences for three constant $e$ 's of $0.55,0.70$, and 0.85 . (a) For the frequency group of $150,183.3 \pm 3$, and $183.3 \pm 7 \mathrm{GHz}$. (b) For the frequency group of $220,183.3 \pm 3$, and $183.3 \pm 7$ $\mathrm{GHz}$. For $e=0.70$, calculated data points with $T_{s} \pm 5 \mathrm{~K}$ are shown for surface temperature effect.

to obtain PW from the MIR measurements along the ER-2 aircraft flight track.

\section{RETRIEVAL ALGORITHM}

The algorithm of Miao [1] utilizes three frequency channels near $183.3 \mathrm{GHz}$ from the SSM/T-2 sensor onboard the DMSP F-11 satellite to retrieve PW. Using the three channels at 183.3 $\pm 1,183.3 \pm 3$, and $183.3 \pm 7 \mathrm{GHz}$ has the distinct advantage that the retrieval is not sensitive to frequency dependence of surface parameters; but the retrieval is limited to PW values of $\leq$ $0.15 \mathrm{~g} / \mathrm{cm}^{2}$. For PW values $>0.15 \mathrm{~g} / \mathrm{cm}^{2}$, Miao [1] uses measurements from the three channels at $150,183.3 \pm 3$, and 183.3 $\pm 7 \mathrm{GHz}$, assuming that surface emissivity is the same in the frequency range of 150-180 GHz. This latter assumption, if not correct, could introduce a significant error in the estimation of $\mathrm{PW}$, as demonstrated from results of the MIR measurements in the next section. Besides the five channels between $90-183 \mathrm{GHz}$ covered by the SSM/T-2, the MIR provides another channel at $220 \mathrm{GHz}$. This additional capability allows a reliable estimation of PW, while exploring a possible frequency dependence of surface emissivity at the same time.

To arrive at the algorithm, similar to that of Miao [1] by assuming frequency-independent surface emissivities, for the re- 

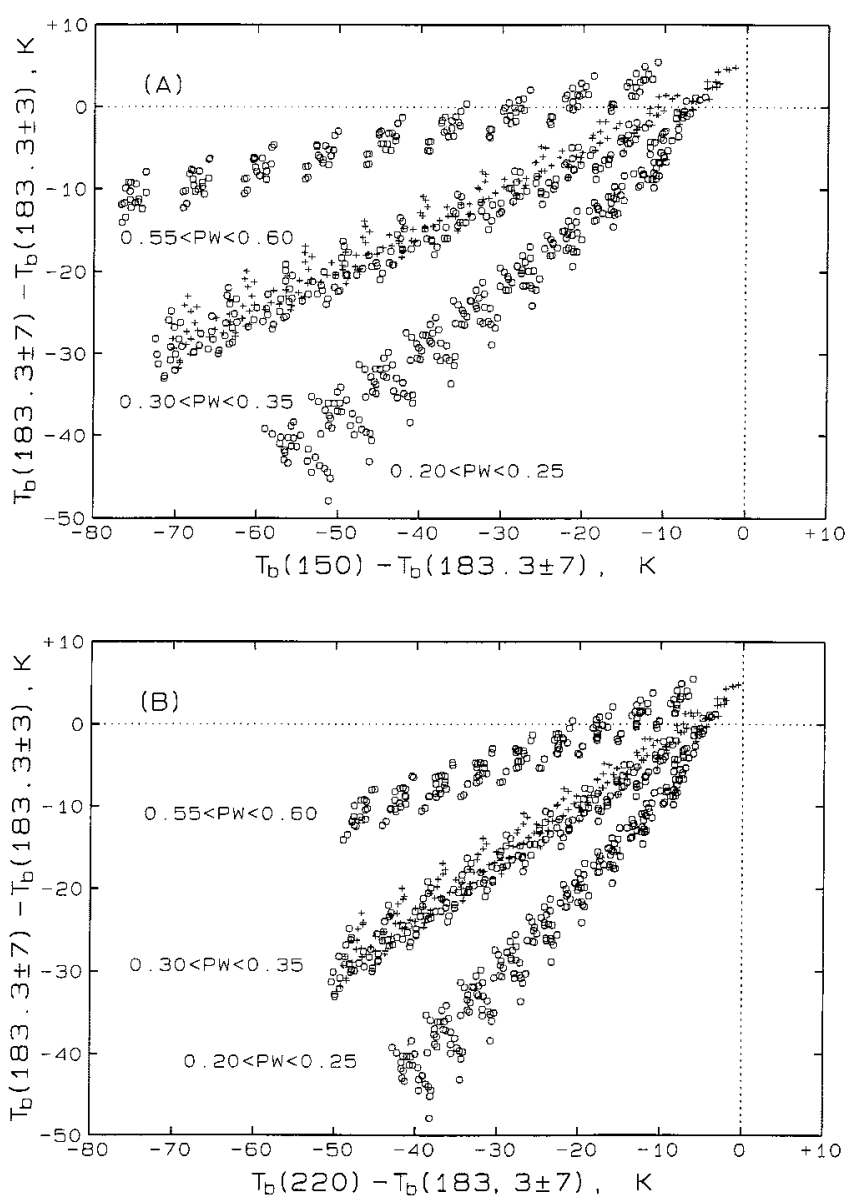

Fig. 5. Scatter plots of brightness temperature differences for three PW ranges of $0.20-0.25,0.30-0.35$, and $0.55-0.60 \mathrm{~g} / \mathrm{cm}^{2}$. (a) For the frequency froup of $150,183.3 \pm 3$, and $183.3 \pm 7 \mathrm{GHz}$. (b) For the frequency group of 220, 183.3 \pm 3 , and $183.3 \pm 7 \mathrm{GHz}$. The symbols for the data in the PW range of $0.30-0.35$ have the same meaning as that of Fig. 4.

trieval of PW in the arctic region, we first calculated the brightness temperatures for the MIR channels at 150, 183.3 $\pm 3,183.3$ \pm 7 , and $220 \mathrm{GHz}$. The rawinsonde data used for these calculations were obtained at SHEBA camp and Barrow over the period of March-June 1998. The statistics of temperature and relative humidity profiles as well as the distribution of PW from these data are shown in Fig. 3. Plots (A), (C), and (E) are for Barrow, and plots (B), (D), and (F), for SHEBA camp. The solid and dashed curves in plots (A), (B), (C), and (D), respectively, give the average and standard deviations of temperature and humidity profiles. The average temperature profiles from these two locations are quite comparable, while the standard deviation of temperature at SHEBA camp is larger at high altitudes $(>10$ $\mathrm{km})$. It can be seen from the comparison of plots (C) and (D) that the air at SHEBA is generally much drier at altitudes $>12$ $\mathrm{km}$ than that at Barrow. The PW values at SHEBA are $<1.0$ $\mathrm{g} / \mathrm{cm}^{2}$ during this period, while a significant fraction of those at Barrow are $>1.0 \mathrm{~g} / \mathrm{cm}^{2}$. In the radiative transfer calculations, the absorption coefficients from various atmospheric gases are derived from the 1989 version of the MPM of Liebe [9]. There are several different versions of MPM [9]-[11], but it is not clear that any one is better than the other. Furthermore, these versions and another recent model [12] differ mainly in the continuum of
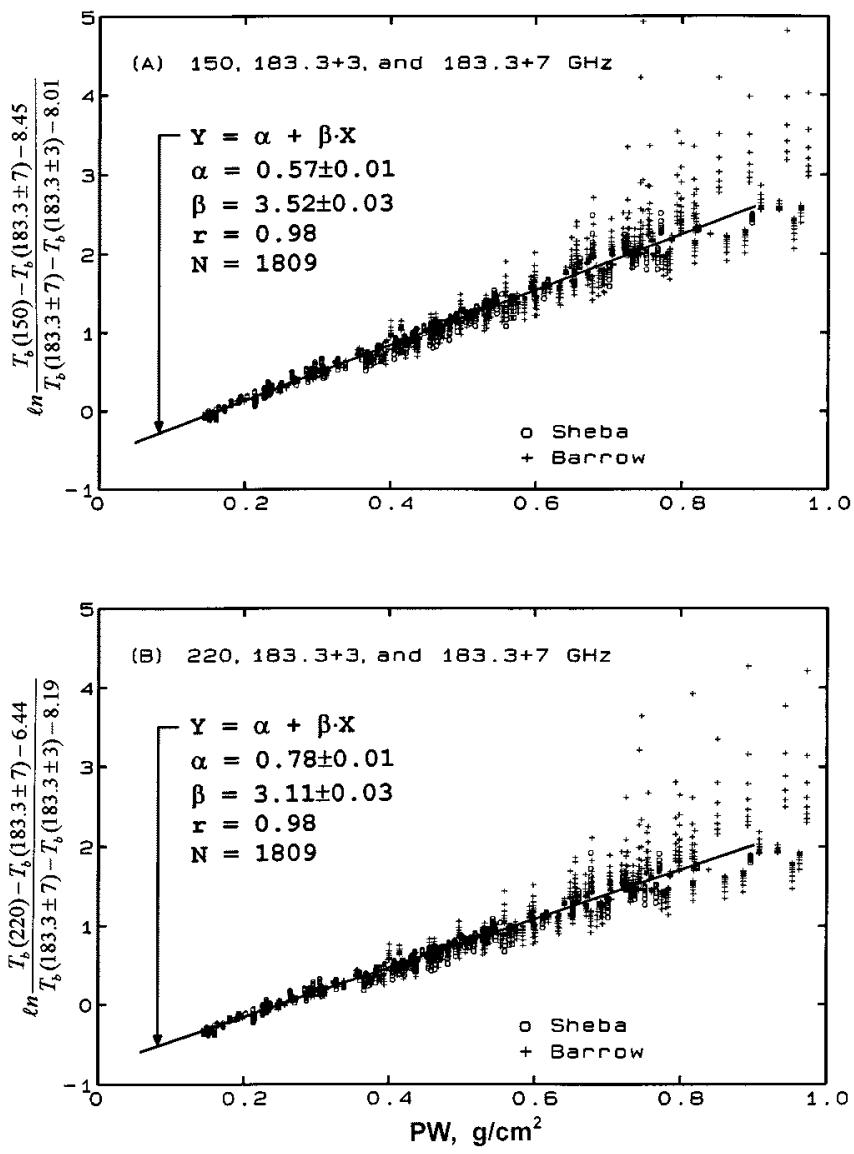

Fig. 6. Scatter plots showing the functional dependence of PW on $T_{b}(\nu)$ of selected MIR channels. (a) $150,183.3 \pm 3$, and $183.3 \pm 7 \mathrm{GHz}$ and (b) 220 , $183.3 \pm 3$, and $183.3 \pm 7 \mathrm{GHz}$. The straight lines and associated parameters are results of linear regression based on data points with $\mathrm{PW} \leq 0.6 \mathrm{~g} / \mathrm{cm}^{2}$.

the absorption spectrum. Under the relatively dry conditions discussed in this paper, these differences are not expected to have a major impact on the retrieval results. The surface emissivity for all four frequencies is varied from 0.50 to 0.95 . Since the surface temperature $T_{s}$ is not independently measured, the temperature reading $(\sim 265 \mathrm{~K})$ at the surface level of rawinsonde data is treated as $T_{s}$ in the calculations. It turns out that this temperature reading is close to the ones measured by an instrument onboard the C-130 aircraft flying over the same region as the ER-2 aircraft (see Section IV).

The calculated brightness temperatures are formed into two different groups of 150, 183.3 $\pm 3,183.3 \pm 7 \mathrm{GHz}$ (group I), and $220,183.3 \pm 3,183.3 \pm 7 \mathrm{GHz}$ (group II), each providing an algorithm for independent estimation of PW. In Fig. 4(a), a scatter plot of brightness temperature differences from the first group is shown for three different surface emissivities $(e)$ of $0.55,0.70$, and 0.85 . For $e=0.70$, calculated results with $T_{s}+5$ and $T_{s}-5$, are displayed to show the effect of surface temperature changes. The similar results from the other group at 220, $183.3 \pm 3$, and $183.3 \pm 7 \mathrm{GHz}$ are shown in Fig. 4(b). It is clear from these plots that for a given $e$, the data points from all $\mathrm{PW}$ values, regardless of temperature and relative humidity profiles, are formed into a well-defined group. The changes in $T_{s}$ by $\pm 5 \mathrm{~K}$ shift the data points at $e=0.70$. The shift appears to show the same effect as increasing or decreasing $e$ by about $0.01-0.02$. 


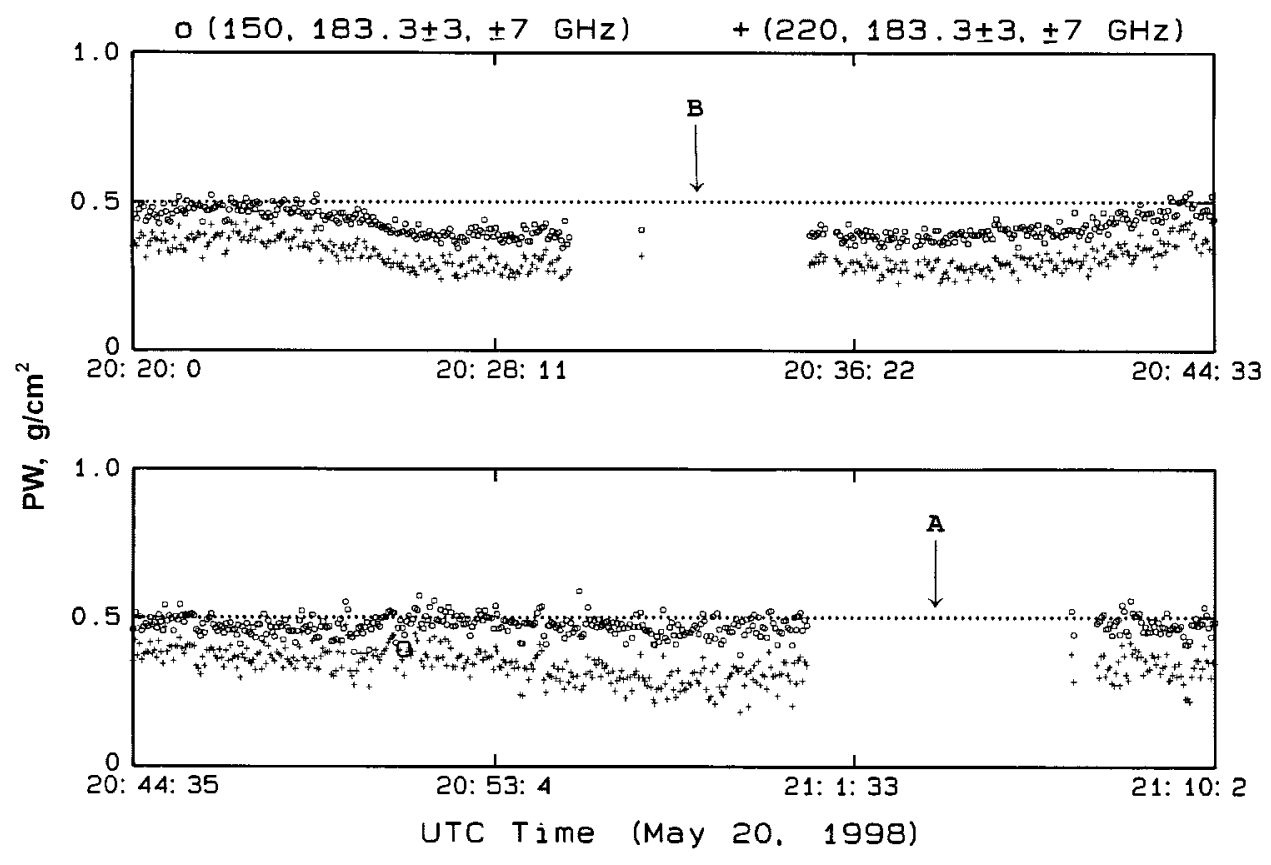

Fig. 7. Variations of PW along the flight segment $\mathrm{AB}$ (Fig. 1) retrieved from the MIR measurements at two different combinations of frequencies. The large open circle at $\sim 2050 \mathrm{UTC}$ is the PW derived from the near-concurrent radiosonde observation at Barrow.

Fig. 5 shows the effect of changing the PW values on the scatter plot of brightness temperature differences (A) for group I and (B) for group II. Three groups of data points with different ranges of $\mathrm{PW}$ values are shown in the figure. Within each group, values of e are varied from 0.50 to 0.95 in step of 0.05 . Clusters in each PW group of data are caused by the 0.05 step in emissivity change. For the group with $0.30<\mathrm{PW}<0.35$, the symbols have the same significance as those in Fig. 4 when in reference to changes in $T_{s}$. It appears that there is a slight dependence of PW on the changes of $T_{s}$. The effect of this dependence on PW estimation is elaborated further in Section V. Clearly, the values of $T_{b}(183.3 \pm 7)-T_{b}(183.3 \pm 3)$ practically vary linearly with those of both $T_{b}(150)-T_{b}(183.3 \pm 7)$ and $\mathrm{Tb}(220)-\mathrm{Tb}(183.3(7)$. A linear regression applied to a given group of data results in a slope that is uniquely related to the PW value of that group. Thus, for each frequency group, if a common intersection of these regression lines can be found, then the slope and therefore the PW value can be determined from the radiometric measurements of the three frequency channels.

It turns out that these regression lines do not intersect at a common point, as was found earlier by Miao [1]. But the intersection points from pairs of regression lines lie in a close neighborhood. We take the average of these intersection points and treat it as the common intersection point for the estimation of slopes and PW values from the radiometric measurements. The error introduced by this process was found to be smaller than that caused by a measurement uncertainty of $\pm 1 \mathrm{~K}$, which is discussed in Section V. The slope $\eta$ of the frequency group I, therefore, can be written as

$$
\eta=\frac{T_{b}(150)-T_{b}(183.3 \pm 7)-Y_{0}}{T_{b}(183.3 \pm 7)-T_{b}(183.3 \pm 3)-X_{0}}
$$

with $Y_{0}=8.45 \mathrm{~K}$ and $X_{0}=8.01 \mathrm{~K}$. For the frequency group II, $Y_{0}$ and $X_{0}$ are found to be $6.44 \mathrm{~K}$ and $8.19 \mathrm{~K}$, respectively. These results with above $Y_{0}$ and $X_{0}$ values are derived for the arctic region during the March-June period. The results could be slightly different for other region or different seasons [1], [2].

Miao found that the logarithm of $\eta$ is almost linarly proportional to PW, i.e.

$$
\ln \eta=\alpha+\beta \cdot P W .
$$

To see whether this relation holds true for the calculated parameters above, the values of $\ln \eta$ and PW are plotted in Fig. 6(a) and (b), respectively, for the frequency group I and group II. Two different symbols are used to represent data from SHEBA and Barrow stations. For $\mathrm{PW} \leq 0.60 \mathrm{~g} / \mathrm{cm}^{2}$, data from both stations are well mixed, suggesting insignificant effects due to variations of the temperature and relative humidity profiles. The relation between $\ln \eta$ and $\mathrm{PW}$ is quite linear from both frequency groups, confirming the results of Miao [2]. There is more data spread for $0.40 \leq \mathrm{PW} \leq 0.60 \mathrm{~g} / \mathrm{cm}^{2}$, a significant fraction of it caused by changes in surface emissivities in radiative transfer calculations. For PW $>0.60 \mathrm{~g} / \mathrm{cm}^{2}$, there is a large scatter of data points, especially those from the Barrow station. This implies that it is less reliable to estimate PW from this approach when PW > $0.60 \mathrm{~g} / \mathrm{cm}^{2}$. Applying a linear regression to data with $\mathrm{PW} \leq$ $0.60 \mathrm{~g} / \mathrm{cm}^{2}$ results in the slope $(\beta)$, intercept $\alpha$ ), and correlation coefficient $((r)$ for each frequency group shown in the figure. The correlation is excellent for both groups. The standard deviation for the estimation of slope is less than $2 \%$, and that for the estimation of intercept is on the order of $1 \%$. These linear equations for $\ln \eta$ and PW are applied to the MIR measurements for the estimation of $\mathrm{PW}$, and the results are presented in the next section. 


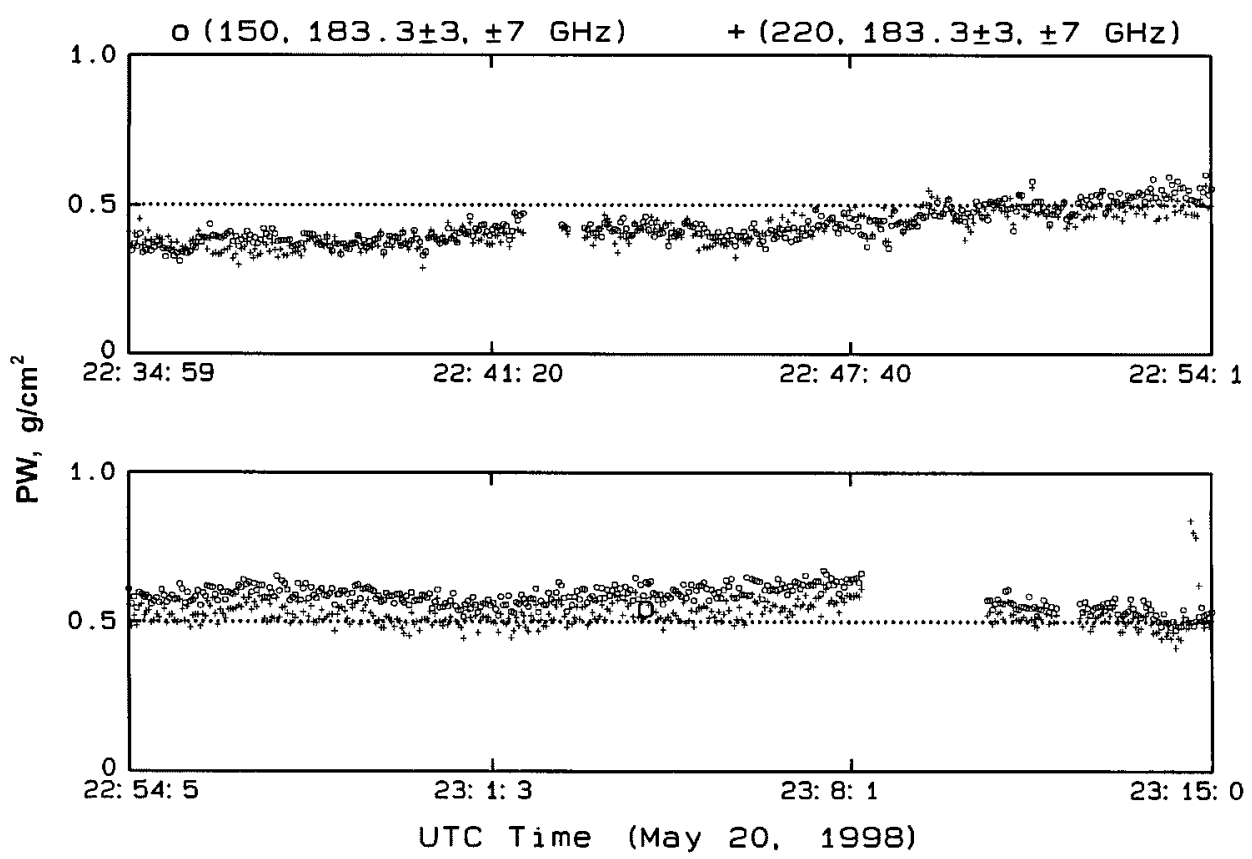

Fig. 8. Variations of PW along the flight segment CD (Fig. 1) retrieved from the MIR measurements at two different combinations of frequencies. The large open circle at $\sim 2304$ UTC is the PW derived from the near-concurrent radiosonde observation at SHEBA camp.

\section{RESULTS}

Fig. 7 shows the estimated PW values along the ER-2 flight segment AB displayed in Fig. 1. The PW values in open circles are derived from the measurements of frequency group I, while those in + signs from the measurements of group II. The large open circle in the bottom panel, at 2050 UTC, is the PW value calculated from the Barrow rawinsonde observation at 0000 UTC on May 21, 1998. The two gaps in the data correspond to the two endpoints (the arrows relate to locations A and B in Fig. 1) where the aircraft are making turns, i.e., the estimated PWs are limited to the time intervals when the aircraft roll angle is $<3^{\circ}$. The PWs near both ends of each data gap are derived from measurements over the same region and they agree well in value, suggesting repeatability of the measurements. It is clear that the PW values estimated from the frequency group I are generally higher than those from the frequency group II. The difference is larger near endpoint A than that near endpoint B. The PWs estimated from Group I at 2050 UTC near Barrow station are about $0.1 \mathrm{~g} / \mathrm{cm}^{2}$ higher than that derived from the rawinsonde data.

The similar plot from the flight segment CD (Fig. 1) is shown in Fig. 8. The two data gaps at $\sim 2242$ UTC and $\sim 2309$ UTC again are caused by directional change of the aircraft when roll angle $>3^{\circ}$. The large circle at 2304 UTC (over SHEBA camp) gives the value of PW calculated from SHEBA rawinsonde observation at 0001 UTC on May 21, 1998. It can be seen that, in the top panel, most of the estimated PW values from the two frequency groups are quite comparable. In the bottom panel, there are more differences between the PW values estimated from the two frequency groups. These differences are smaller compared to those in Fig. 7. These variable differences in the estimated PWs are likely caused by two factors. First, as pointed out previously, the MIR measurements at $150 \mathrm{GHz}$ could be on the low side. The impact of this measurement error on the estimation of PW is further elaborated in the next section. Next, the assumption on frequency-independent surface emissivity in the algorithm development could be erroneous. The effect of surface temperature is ruled out because of its insignificant impact on the estimated PWs, as shown in the next section.

To allow for a possible frequency dependence of surface emissivity $e$, we assume a simple form as following:

$$
e=e_{0}+(\gamma(\nu-150))
$$

where the frequency $\nu$ is limited to the range of $150 \leq \nu \leq$ $220 \mathrm{GHz}$, and $\gamma$ is a small number in seconds and can be either positive or negative. This equation was used in the new radiative transfer calculations to obtain the $T_{b}(\nu) \mathrm{s}$ for $\nu=150,183.3$ $\pm 3,183.3 \pm 7$, and $220 \mathrm{GHz}$, with $\gamma$ varying from -0.001 to +0.001 in 0.0002 steps and $e_{0}$ varying from 0.50 to 0.95 in 0.05 steps. For each $\gamma$ value, the procedure of the last section was repeated to obtain the values of four parameters $\alpha, \beta, X_{0}$, and $Y_{0}$. When values from each of these parameters were plotted against the corresponding $\gamma$ values, a linear relation was found to a very good approximation. Thus, a linear regression was applied to the values of $z$ (which stands for any of $\alpha, \beta, X_{0}$, and $Y_{0}$ ) and $\gamma$, and regression coefficients $a$ and $b$ were found in the following equation:

$$
z=a+b \cdot \gamma \cdot
$$

The values of $a$ and $b$ for each of the four parameters were tabulated in Table I for both frequency groups. In the process of retrieving PW from each MIR measurement, $\gamma$, and therefore the four parameters $\alpha, \beta, X_{0}$, and $Y_{0}$, were adjusted in each iteration until the retrieved values of PW from both frequency groups agreed to within $\pm 0.005 \mathrm{~g} / \mathrm{cm}^{2}$. 


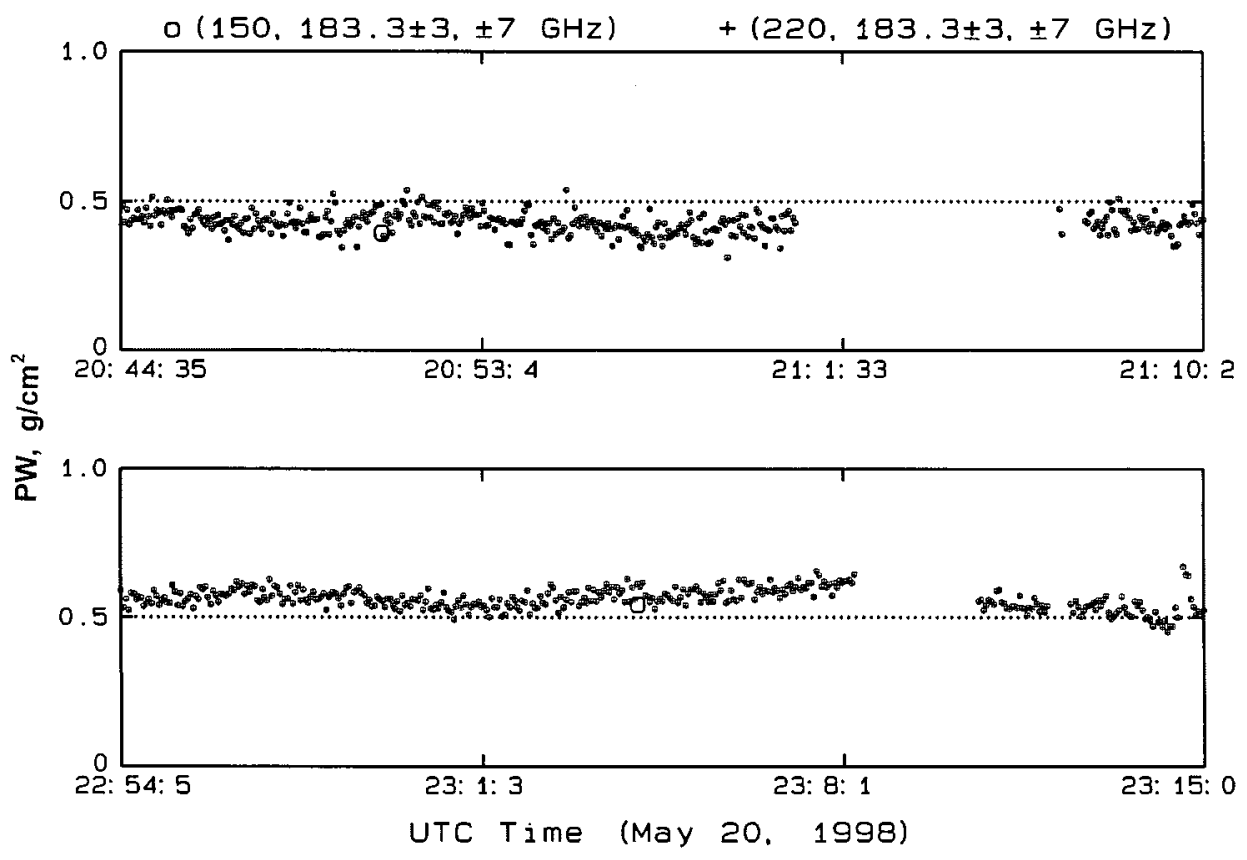

Fig. 9. Variations of retrieved PW values along portions of flight segments $\mathrm{AB}$ and $\mathrm{CD}$. The retrievals are based on surface emissivity linearly dependent on frequency that is allowed to vary until the PW values derived from the two sets of frequency combinations agree to within $\pm 0.02 \mathrm{~g} / \mathrm{cm}^{2}$. The open circles are transferred from Figs. 7 and 8.

TABLE I

PARAMETERS DERIVED FROM LINEAR REGRESSION OF (4)

\begin{tabular}{ccccr}
\hline & \multicolumn{2}{c}{ Frequency Group I } & \multicolumn{2}{c}{ Frequency Group II } \\
& $a$ & \multicolumn{1}{c}{$b$} & \multicolumn{1}{c}{$a$} & \multicolumn{1}{c}{$b$} \\
\hline$\alpha$ & -0.571 & 21.15 & -0.779 & -11.98 \\
$\beta$ & 3.520 & -35.27 & 3.107 & 31.89 \\
$X_{0}$ & 8.01 & -397.62 & 8.19 & 861.31 \\
$Y_{0}$ & 8.45 & -7070.80 & 6.43 & 7582.10 \\
\hline
\end{tabular}

Fig. 9 shows the results from this approach. The top panel covers the same period as the bottom panel in Fig. 7, while the bottom panel covers the same period as the bottom panel of Fig. 8. All the symbols in this figure, including the large circles, have the same meaning as those in the previous two figures. Clearly, the PW values estimated from both frequency groups agree very well, as required in the retrieval process. All the data points that appear in the bottom panels of Figs. 7 and 8 are also present in this figure, i.e., there is no single dropoff of data points from this new retrieval approach. At times of $\sim 2050$ UTC and 2304 UTC (corresponding to flight over Barrow and SHEBA camp, respectively), the estimated PW values are about $0.02 \mathrm{~g} / \mathrm{cm}^{2}$ higher than those derived from the rawinsonde data. These slight differences are not more than that resulted from the uncertainty in the radiometric measurements discussed in the next section. Notice that, on this particular day, the air is drier in the neighborhood of Barrow $\left(\sim 0.4 \mathrm{~g} / \mathrm{cm}^{2}\right)$ than near the SHEBA camp $\left(\sim 0.6 \mathrm{~g} / \mathrm{cm}^{2}\right)$, as reflected from the PW values derived from both rawinsondes and MIR measurements.

Fig. 10(a) and (b) shows the distribution of $\gamma$ and dPW values resulting from the retrival process that satisfy the criteria PW $\leq 0.60 \mathrm{~g} / \mathrm{cm}^{2}$ from the entire flight on May 20 . dPW is the difference between the PW derived from the MIR measurements
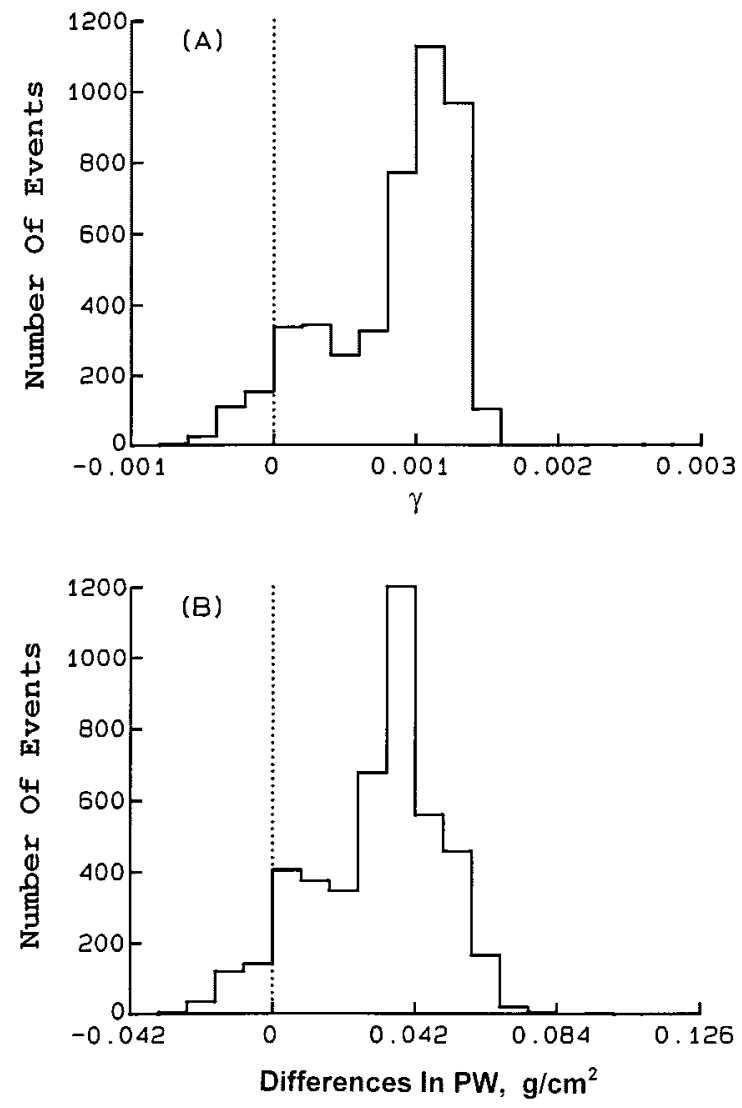

Fig. 10. Histogram showing distribution of (a) the parameter $\gamma$ and (b) the differences in the estimated PW values. Notice that $\gamma>0$ most of the time, implying that surface emissivity increases with frequency at high frequencies $\geq 150 \mathrm{GHz}$.

of group I channels assuming frequency-independent surface emissivities (results in Figs. 7 and 8) and that derived from 
the assumption of frequency-dependent surface emissivities (Fig. 9). It is clear from the figure that in most cases, $\gamma$ is positive, which implies a surface emissivity increasing with $\nu$ in the range of $150 \leq \nu \leq 220 \mathrm{GHz}$. In the region near Barrow, corresponding to data coverage of Fig. 7, positive values of $\gamma$ are needed to bring together the PWsestimated from the two frequency groups. A comparison of plots (A) and (B) suggests that a change in $\gamma$ of about 0.001 is required to reduce $\mathrm{dPW}$ by about $0.04 \mathrm{~g} / \mathrm{cm}^{2}$. Near the SHEBA camp, corresponding to the data coverage of Fig. $8, \gamma$ values are slightly positive (most of the bottom panel in Fig. 8) or close to zero (most of the top panel in Fig. 8). This suggests a weak dependence of $e$ on $\nu$ in this region. The largest positive $\gamma$ value of 0.0016 from the figure would give an increase of $e$ from $150 \mathrm{GHz}$ to 220 $\mathrm{GHz}$ of about 0.11 . Changes of this magnitude in $e$ between the frequency range of $90-157 \mathrm{GHz}$ have been observed over sea ice and snow by Hewison and English [14].

Although precise values of $e$ cannot be derived without concurrent $T_{s}$ measurements, a crude estimation can be made and compared with the results of Hewison and English [14]. During the time of the ER-2 aircraft flight, a National Center for Atmospheric Research (NCAR) C-130 aircraft also flew over the same region that provided remote $T_{s}$ estimation (J. Haggerty, Univ. Colorado, personal communication). The C-130 aircraft measurements give $T_{s}$ values of $\sim 263 \mathrm{~K}$ near Barrow and $\sim 265$ $\mathrm{K}$ near SHEBA camp. Radiative transfer calculations based on these $T_{s}$ values and nearly concurrent rawinsonde data acquired from these two sites result in an emissivity-dependent array of $T_{b}$ values. These calculated $T_{b}$ 's are compared with those measured by the MIR to determine $e$. The results give $e$ values of about $0.70,0.68,0.75$, and 0.77 at $89,150,183.3$, and $220 \mathrm{GHz}$, respectively, near Barrow. Near the SHEBA camp, the corresponding values in sequential order are $0.73,0.65,0.61$, and 0.69 . Instead of increasing or decreasing with frequency as assumed in the form of (3), the lowest $e$ occurs at $183.3 \mathrm{GHz}$. This corresponds to the weak dependence of $e$ on $\nu$ discussed in the previous paragraph. The estimated $e$ values at 89 and $150 \mathrm{GHz}$ are comparable to those measured by Hewison and English [14] over fast ice, deep dry snow, or lake ice plus snow.

\section{DISCUSSION}

The calibration of the MIR radiometric measurements is based on two external calibration targets that are maintained at the temperatures of about $330 \mathrm{~K}$ and $250 \mathrm{~K}$ (at the ER-2 aircraft's cruising altitude of $\sim 20 \mathrm{~km}$ ) [5]. The physical temperatures of these targets are continuously monitored to better than $\pm 0.1 \mathrm{~K}$. During each scan cycle of about $3 \mathrm{~s}$, the scan mirror is directed to view at these targets for $0.15 \mathrm{~s}$ each. Beam efficiency and local oscillator reradiation, however, limit the calibration to about $\pm 1 \mathrm{~K}$ in the $\mathrm{Tb}$ range of $250-300 \mathrm{~K}$. For the measured $T_{b}$ values of $\sim 200 \mathrm{~K}$ outside the range defined by the calibration targets, like those for some of the channels in Fig. 2, the calibration accuracy is not expected to be worse than $\pm 1.5 \mathrm{~K}$. The standard deviation of the retrieval of $\mathrm{PW}$ corresponding to the accuracy of the radiometric measurements can be estimated from (5), shown at the bottom of the page, based on (1) and (2).

Here, $T_{b 1}$ and $T_{b 2}$ stand for $T_{b}$ (183.3 pm 3) and $T_{b}$ (183.3 \pm 7 ), respectively, and $T_{b 3}$ assumes either $T_{b}$ (150) or $T_{b}$ (220). Near Barrow, where the estimated PW values are $\sim 0.4 \mathrm{~g} / \mathrm{cm}^{2}$, the measured $T_{b}(150), T_{b}(183.3 \pm 3), T_{b}(183.3 \pm 7)$, and $T_{b}$ (220) are about $185,259,243$, and $216 \mathrm{~K}$, respectively. With $\delta T_{b 1} \cong \delta T_{b 2} \cong \delta T_{b 3} \cong 1.5 \mathrm{~K}$ and $X_{0}$ and $Y_{0}$ values of about 6 , the estimated values of $\delta P W$ are about $0.033 \mathrm{~g} / \mathrm{cm}^{2}$ and $0.035 \mathrm{~g} / \mathrm{cm}^{2}$ for the frequency groups I and II, respectively. At SHEBA camp, the estimated PW values are about $0.6 \mathrm{~g} / \mathrm{cm}^{2}$, and the measured $T_{b}(150), T_{b}(183.3 \pm 3), T_{b}(183.3 \pm 7)$, and $T_{b}$ (220) are about 194, 257, 249, and $220 \mathrm{~K}$, respectively. The corresponding $\delta P W$ values are estimated to be about 0.047 $\mathrm{g} / \mathrm{cm}^{2}$ and $0.075 \mathrm{~g} / \mathrm{cm}^{2}$ for the frequency groups I and II, respectively. For the frequency group II of $T_{b}(220), T_{b}(183.3 \pm 3)$, and $T_{b}(183.3 \pm 7)$, the ratio $\delta P W / P W$ varies from about $9 \%$ for $\mathrm{PW} \cong 0.4 \mathrm{~g} / \mathrm{cm}^{2}$ to $13 \%$ for $\mathrm{PW} \cong 0.6 \mathrm{~g} / \mathrm{cm}^{2}$. For the frequency group I of $T_{b}$ (150), $T_{b}\left(183.3 \pm 3\right.$ ), and $T_{b}$ (183.3 \pm 7), $\delta P W / P W$ remains relatively constant at about $8 \%$ at both locations. It is pointed out that $\delta P W$ could become large when values of $T_{b 1}$ and $T_{b 2}$ or $T_{b 2}$ and $T_{b 3}$ are comparable. This would occur when PW $>0.6 \mathrm{~g} / \mathrm{cm}^{2}$, or when surface emissivity is relatively large (e.g., $e>0.85$ ).

The negative bias of the $150 \mathrm{GHz}$ measurements mentioned in the previous section would affect the estimation of PW. Because the temperatures of the cold and hot calibration targets were maintained at about $250 \mathrm{~K}$ and $328 \mathrm{~K}$ during the aircraft flight, this bias was not likely to be much more than $2-3 \mathrm{~K}$ in the observed brightness temperature range of 180-240 K. To see how this bias would impact the estimated P,W values, we added $2 \mathrm{~K}$ uniformly to the measured $150 \mathrm{GHz} T_{b}$ 's and repeated the above retrieval process. It was found that the estimated PW values were generally lower compared to the previously retrieved ones. This could be qualitatively observed from data displayed in Fig. 5(a). Increasing $T_{b}(150)$ alone would shift data points to the right and make $T_{b}(150)-T_{b}$ (183.3 \pm 7 ) less negative. Lower PW values would be obtained as a consequence. The associated $\gamma$ s were lower or higher than before, depending on whether $\gamma$ was negative or positive, i.e., the added $T_{b}$ bias increased the surface emissivity at $150 \mathrm{GHz}$ and reduced PW estimation at the same time. For example, at $\sim 2050$ UTC near Barrow, the newly estimated PW values were about $0.007 \mathrm{~g} / \mathrm{cm}^{2}$ lower than the previously estimated ones, which were closer to that derived from the rawinsonde data. Similar results were obtained at around 2304 UTC near the location of the SHEBA camp.

$$
\delta P W=\frac{\sqrt{\delta T_{b 1}^{2} \cdot\left(T_{b 3}-T_{b 2}-X_{0}\right)^{2}+\delta T_{b 2}^{2} \cdot\left(T_{b 1}-T_{b 3}-X_{0}-Y_{0}\right)^{2}+\delta T_{b 3}^{2} \cdot\left(T_{b 2}-T_{b 1}-Y_{0}\right)^{2}}}{\beta \cdot\left(T_{b 2}-T_{b 1}-Y_{0}\right) \cdot\left(T_{b 3}-T_{b 2}-X_{0}\right)} .
$$



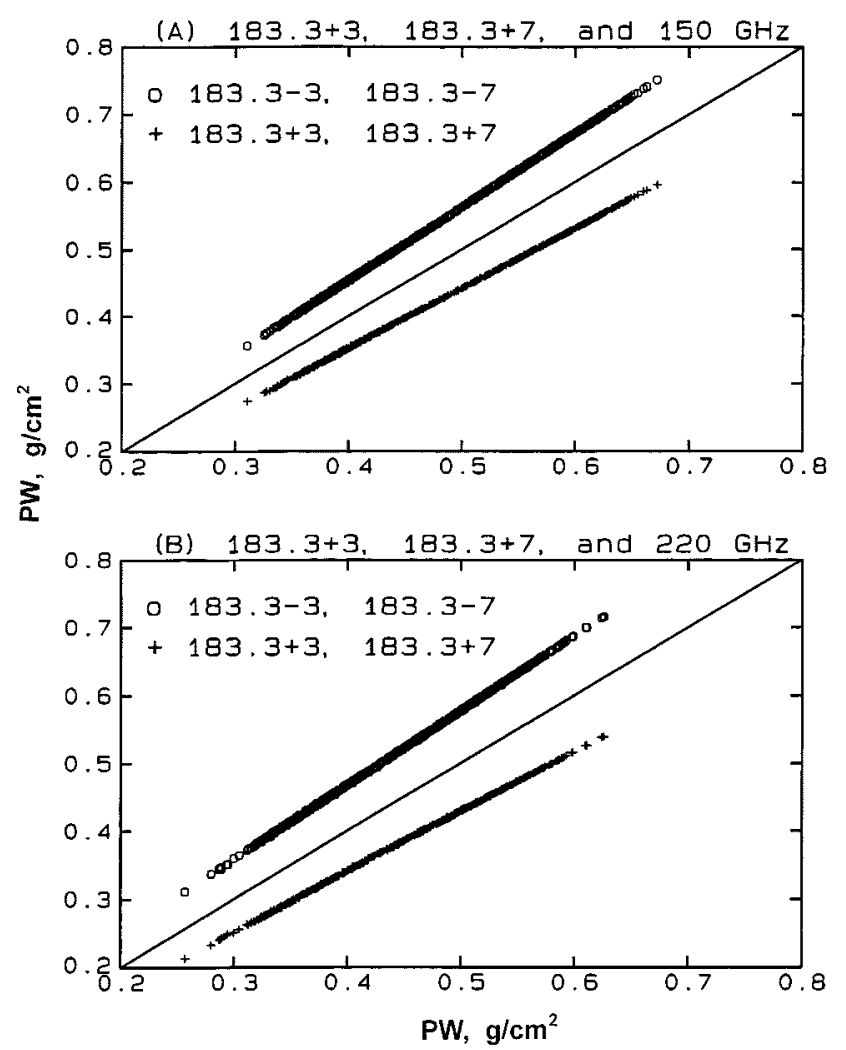

Fig. 11. Comparison of PW values estimated from algorithms with considerations of single side-band and double side-band measurements near 183.3 GHz. (a) Frequency group of $150,183.3 \pm 3$, and $183.3 \pm 7 \mathrm{GHz}$, and (b) $220,183.3 \pm 3$, and $183.3 \pm 7 \mathrm{GHz}$.

When the atmosphere is relatively dry, the asymmetry in the shape of the $183.3 \mathrm{GHz}$ absorption about the peak frequency becomes more conspicuous. In the development of the retrieval algorithms in the previous sections, it is necessary to take into account the double side-band nature of the radiometric measurements for the $183.3 \mathrm{GHz}$ channels because of this asymmetry. To see the magnitude of errors that the retrievals might introduce if the double side-band radiometric measurements are not accounted for, we have reformulated algorithms with single side-band radiative transfer calculations. The PW values estimated from these new algorithms are compared with those retrieved from the double side-band algorithm in Fig. 11(a) and (b) for frequency groups I and II. Here, the single side-band results are plotted along the vertical axis and the double side-band ones, along the horizontal axis. Open circles stand for the lower side-band data, and + signs for the upper side-band data. Clearly, the differences between the single side-band and the double side-band results could be substantial. The errors in estimating PW by single side-band algorithms could range from about $0.06 \mathrm{~g} / \mathrm{cm}^{2}$ to $0.09 \mathrm{~g} / \mathrm{cm}^{2}$, depending on the magnitude of PW. The lower side-band algorithm gives an overestimation of PW, while the upper side-band one, an underestimation of PW. These results apply to both frequency groups.

It was stated in Section IV that imprecise knowledge of surface temperature is not critical in estimating PW with this algorithm. This is demonstrated in Fig. 12, where the PW values

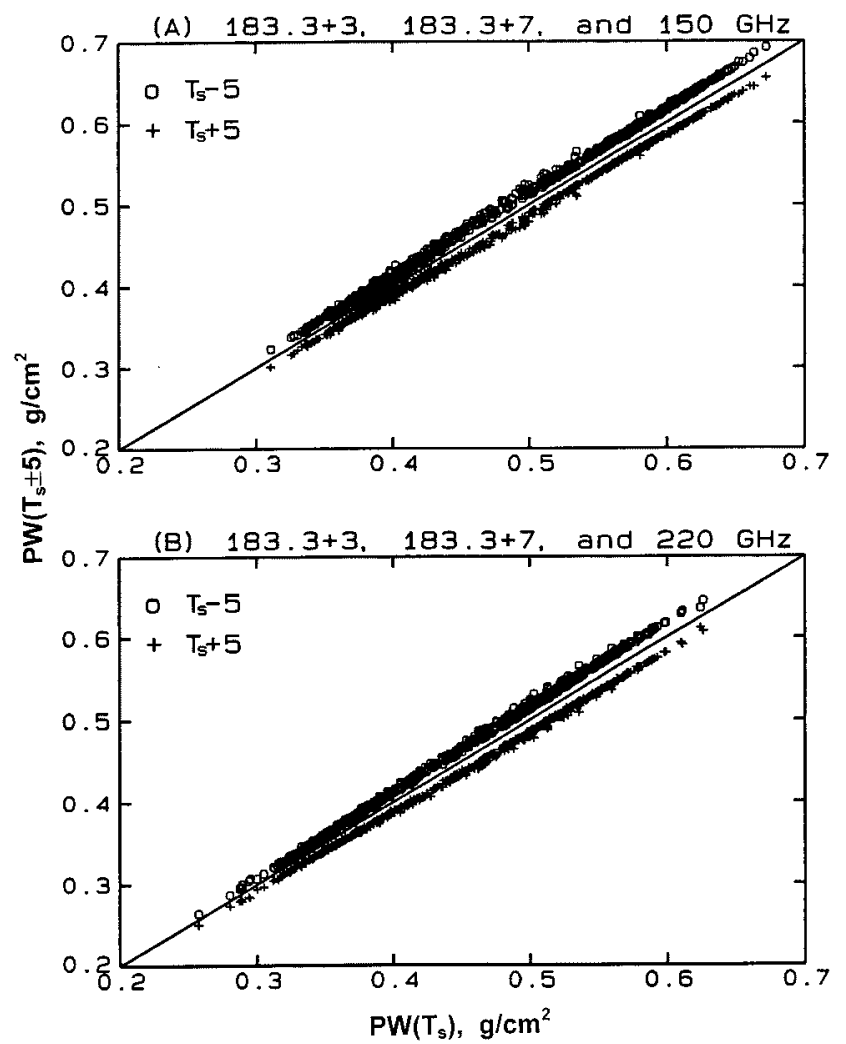

Fig. 12. Plot showing the effect of surface temperature changes on the retrieval of PW. (a) Frequency group of 150, $183.3 \pm 3$, and $183.3 \pm 7 \mathrm{GHz}$ and (b) frequency group of $220,183.3 \pm 3$, and $183.3 \pm 7 \mathrm{GHz}$.

along the vertical are derived from the algorithms formulated by the same double side-band radiative transfer calculations, but with values of the original surface temperature $T_{s}$ substituted by $T_{s}+5$ and $T_{s}-5 \mathrm{~K}$. The PW values derived from the algorithm formulated by original radiative transfer calculations with $T_{s}$ are given along the horizontal axis. Again, the illustration is made for both frequency groups in plots (A) and (B). Open circles are the results using algorithm with $T_{s}-5$ radiative transfer calculations, while the + signs are those using algorithm with $T_{s}+5$ radiative transfer calculations. It is clear that the $\pm 5 \mathrm{~K}$ changes in $T_{s}$ would introduce about \pm 0.01 to $\pm 0.02 \mathrm{~g} / \mathrm{cm}^{2}$ differences in the estimation of PW over the entire $\mathrm{PW}$ range of $\leq$ $0.6 \mathrm{~g} / \mathrm{cm}^{2}$. This is small compared to the errors of PW estimation caused by the uncertainty of the MIR radiometric measurements discussed above. Thus, an imprecise knowledge of surface temperature would not have a major impact on the development of retrieval algorithm of this kind. However, PW is the only parameter that can be retrieved with reliability in this approach. To obtain values of surface emissivity besides PW, and thereby study properties of snow cover and sea ice at these frequencies, simultaneously accurate measurements of surface temperatures are required.

\section{CONCLUSION}

Radiometric measurements made by the MIR onboard the NASA ER-2 aircraft over the arctic region on May 20, 1998 were used to estimate the precipitable water PW along the 
aircraft flight path. The algorithm developed by Miao [1] for estimation of PW from the SSM/T-2 measurements over the Antarctica was adjusted for the Arctic environment and applied to the airborne radiometric measurements. The adjustment to formulation of the algorithm was made in the radiative transfer calculations, using four months of rawinsonde data (March-June 1998) acquired from Barrow and SHEBA camp. The original algorithm of Miao [1] used the 150, $183.3 \pm$ 3 , and $183.3 \pm 7 \mathrm{GHz}$ channels of the SSM/T-2 to estimate the PW values up to about $0.7 \mathrm{~g} / \mathrm{cm}^{2}$, and it was necessary to assume a frequency-independent surface emissivity in this frequency range. MIR had an additional channel of measurements at $220 \mathrm{GHz}$ and could thus provide data for studying the frequency dependence of surface emissivity. It was found that the assumption of a frequency-independent surface emissivity often could not arrive at the estimation of PW values consistent with the MIR measurements over the entire frequency range of $150-220 \mathrm{GHz}$. A provision was therefore allowed in the algorithm for a surface emissivity that was linearly dependent on frequency over the frequency range of $150-220 \mathrm{GHz}$. The PW values retrieved from this new algorithm were consistent with the MIR measurements over the above frequency range. The estimated PW values also compared favorably with those derived from rawinsonde data at Barrow $\left(\sim 0.4 \mathrm{~g} / \mathrm{cm}^{2}\right)$ and SHEBA camp $\left(\sim 0.6 \mathrm{~g} / \mathrm{cm}^{2}\right)$.

Several factors relevant to probable errors of estimating PW from the MIR measurements were discussed in the paper. First, for the observed brightness temperature range of about 190-260 $\mathrm{K}$ over Barrow and the SHEBA camp, the accuracy of the MIR radiometric measurements was about $\pm 1.5 \mathrm{~K}$. The uncertainty corresponding to this measurement accuracy ranged from $8 \%$ to $13 \%$ of the estimated values of PW. There was a possible negative bias in the measured $T_{b}$ values at $150 \mathrm{GHz}$, and this might be the cause of the retrieved PWs being slightly higher than those calculated from the nearly concurrent rawinsonde data. The errors associated with imprecise knowledge of surface temperatures were found to be small. A $\pm 5 \mathrm{~K}$ change in surface temperature caused a shift of $\sim \pm 0.02 \mathrm{~g} / \mathrm{cm}^{2}$ in the estimated PW values. Finally, it was shown that the double side-band measurements in the $183.3 \mathrm{GHz}$ channels need to be taken into account in the formulation of retrieval algorithms, as the absorption coefficients around the $183.3 \mathrm{GHz}$ peak absorption are highly asymmetric in a dry atmosphere. Omission of this procedure could introduce errors of $0.05-0.10 \mathrm{~g} / \mathrm{cm}^{2}$ in PW estimation.

\section{ACKNOWLEDGMENT}

The authors would like to thank three reviewers for constructive comments on this manuscript. They would also like to thank the NASA FIRE and Sea Ice Project offices for the MIR measurements and data analysis.

\section{REFERENCES}

[1] J. Miao, "Retrieval of atmospheric water vapor content in polar regions using spaceborne microwave radiometry," Dept. Physics, Univ. Bremen, Bremen, Germany, May 1998.
[2] S. L. Moore, "Determination of integrated water vapor over Antarctica utilizing special sensor microwave temperature-2 (SSM/T-2) data," Dept. Meteorol., Texas A\&M Univ., College Station, 1997.

[3] J. C. King and J. Turner, Antarctic Meteorology and Climatology. Cambridge, U.K.: Cambridge Univ. Press, 1997.

[4] J. R. Wang, W. C. Boncyk, L. R. Dod, and A. K. Sharma, "Retrieval of total precipitable water over high-latitude regions using radiometric measurements near 90 and $183 \mathrm{GHz}, " J$. Appl. Meteorol., vol. 31, no. 12, pp. 1368-1378, 1991.

[5] P. Racette, R. F. Adler, J. R. Wang, A. J. Gasiewski, D. M. Jackson, and D. S. Zacharias, "A millimeter-wave imaging radiometer for cloud, precipitation, and atmospheric water vapor studies," J. Atmos. Ocean. Technol., vol. 13, no. 3, pp. 610-619, 1996.

[6] "First ISCCP (International Satellite Cloud Climatology Project) Regional Experiment-III (1994-1999) (FIRE), FIRE Arctic Cloud Experiment Operations Plan," NASA Langley Res. Center FIRE Project Office, Hampton, VA, Feb. 27, 1998.

[7] M. D. King, W. P. Menzel, P. S. Grant, J. S. Myers, G. T. Arnold, S. E. Platnick, L. E. Gumley, S. C. Tsay, C. C. Moeller, M. Fitzgerald, K. S. Brown, and F. G. Osterwisch, "Airborne scanning spectrometer for remote sensing of cloud, aerosol, water vapor, and surface properties," J. Atmos. Ocean Technol., vol. 13, no. 4, pp. 777-794, 1996.

[8] L. Klein and C. Swift, "An improved model for the dielectric constant of sea water at microwave frequencies," IEEE Trans. Antennas Propagat., vol. AP-25, pp. 104-111, 1977.

[9] H. J. Liebe, "MPM-An atmospheric millimeter-wave propagation model," Int. J. Infr. Millimeter Waves, vol. 10, no. 6, pp. 631-650, 1989.

[10] H. J. Liebe and D. H. Layton, Millimeter-Wave Properties of the Atmosphere. Boulder, CO: Nat. Telecommun. Inform. Admin., p. 470.

[11] H. J. Liebe, G. A. Hufford, and M. G. Cotton, "Propagation modeling of moist air and suspended water/ice particle below $1000 \mathrm{GHz}$," in $A G A R D$ 52nd Special Meeting of the Panel on Electromagnetic Wave Propagation. Palma de Mallorca, Spain, May 17-21, 1993, pp. 3-1-3-10.

[12] P. W. Rosenkranz, "Water vapor microwave continuum absorption: A comparison of measurements and models," Radio Sci., vol. 33, pp. 919-928, 1998.

[13] A. P. Stogryn, H. T. Bull, K. Rubayi, and S. Iravanchy, "The microwave permittivity of sea and fresh water," Aerojet Report 1995, GenCorp Aerojet, Azusa, CA.

[14] T. J. Hewison and S. J. English, "Airborne retrievals of snow and ice surface emissivity at millimeter wavelengths," IEEE Trans. Geosci. Remote Sensing, vol. 37, pp. 1871-1879, July 1999.

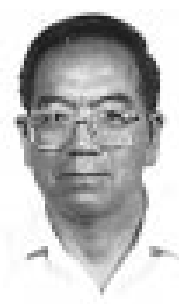

James R. Wang received the B.S. degree in physics from the University of Washington, Seattle, in 1963, and the M.S. and Ph.D. degrees in physics from the University of Chicago, Chicago, IL, in 1964 and 1969 , respectively.

He has been with the NASA Goddard Space Flight Center, Microwave Sensors Branch, Greenbelt, MD, since 1977. His research interest is primarily on the applications of both active and passive microwave techniques for remote sensing of geophysical parameters such as soil moisture, water vapor,

clouds, and precipitation.

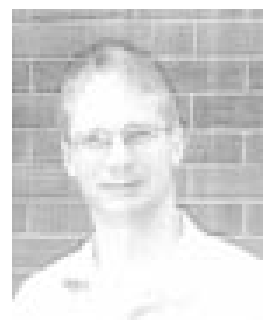

Paul E. Racette received the B.S. and M.S. degrees in electrical engineering from the University of Kansas, Lawrence, in 1988 and 1990, respectively. $\mathrm{He}$ is currently pursuing the Ph.D. degree at the George Washington University, Washington, DC.

$\mathrm{He}$ is an electronics engineer for the National Aeronautics and Space Administration with Goddard Space Flight Center, Greenbelt, MD, where he has worked since July 1990. His work at Goddard involves developing microwave remote sensing instrumentation and remote sensing research.

Dr. Racette serves on IEEE New Technology Directions Committee and the Geoscience and Remote Sensing Society's Instrumentation and Future Technologies Committee. 


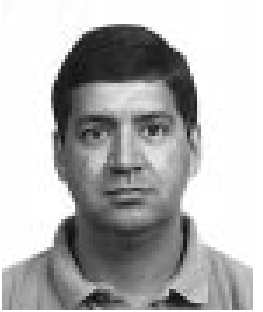

Michael E. Triesky received the B.S. degree in electrical engineering from the University of Pittsburgh, Pittsburgh, PA, in 1994.

$\mathrm{He}$ is an electronics engineer with the National Aeronautics and Space Administration's Goddard Space Flight Center, Greenbelt, MD, where he has worked since May 1992. His work at Goddard involves developing microwave remote sensing instrumentation. 